\title{
Comparison of Fully Coated Anti-Reflux Metal Stenting and Per-Oral Endoscopic Myotomy in Patients with Achalasia: A Propensity Score- Matched Retrospective Study
}

yufen tang

Senior Department of Gastroenterology, the First Medical Center of PLA General Hospital, Beijing,

Peng Jin

Senior Department of Gastroenterology, the First Medical Center of PLA General Hospital, Beijing,

Yu-rong Tao

Department of Gastroenterology, the Seventh Medical Center of PLA General Hospital,Beijing, Hui Xie

Department of Gastroenterology, the Seventh Medical Center of PLA General Hospital,Beijing,

\section{Xin Wang}

Department of Gastroenterology, the Seventh Medical Center of PLA General Hospital,Beijing,

\section{Dongliang Yu}

Department of Gastroenterology, the Seventh Medical Center of PLA General Hospital,Beijing,

\section{Shan Tang}

Department of Gastroenterology, the Seventh Medical Center of PLA General Hospital,Beijing,

Jian-qiu Sheng ( $\nabla$ jianqiu@263.net)

Senior Department of Gastroenterology, the First Medical Center of PLA General Hospital, Beijing,

\section{Research Article}

Keywords: fully coated anti-reflux metal stenting, per-oral endoscopic myotomy

Posted Date: September 30th, 2021

DOl: https://doi.org/10.21203/rs.3.rs-763245/v1

License: (c) (i) This work is licensed under a Creative Commons Attribution 4.0 International License. Read Full License 


\title{
Comparison of fully coated anti-reflux metal stenting and
} per-oral endoscopic myotomy in patients with achalasia: a propensity score-matched retrospective study

Yu-fen Tang, $\mathrm{MM}^{1}{ }^{1}{ }^{*}$, Peng Jin, MD, PhD ${ }^{1}{ }^{2}{ }^{*}$, Yu-rong Tao ${ }^{1 *}$, Hui Xie, $\mathrm{BD}^{1}$, Xin Wang, $\mathrm{BD}^{1}$, Dongliang $\mathrm{Yu}, \mathrm{BD}^{1}$, Shan Tang, $\mathrm{BD}^{1}$, Jian-qiu Sheng , $\mathrm{MD}, \mathrm{PhD}^{1}, 2 *$

Affiliations : ${ }^{1}$ Department of Gastroenterology, the seventh Medical Center of PLA General Hospital, Beijing, China; ${ }^{2}$ Senior Department of Gastroenterology, the First Medical Center of PLA General Hospital, Beijing, China.

*Those authors contributed to this work equally.

*Address all correspondence to: Jian-qiu Sheng,

Department of Gastroenterology

The seventh medical center of PLA General Hospital

Nanmencang 5\#, Dongcheng District

Beijing, China, 100700

Email: jianqiu@263.net

Phone: +86-10-66721014

Fax: $+86-10-66721299$.

\begin{abstract}
Background: Achalasia is a rare primary esophageal motility disorder disease. It is reported that the long-term effect of fully coated anti-reflux metal stent (FCARMS) implantation is satisfactory. Operated by a skilled and experienced endoscopist, the effect of per-oral endoscopic myotomy (POEM) treatment is equivalent to that of surgical myotomy. So far, there is still few evidence to prove FCARMS implantation or POEM which is better for achalasia. The choice of treatment for achalasia is still controversial. The aim of this study is to find a more suitable therapy for achalasia by comparing the efficacy of FCARMS implantation and POEM.
\end{abstract}

Methods: A propensity score (PS) matching (1:2) was used in this retrospective cohort study. Data collected from consecutive patients of Achalasia, receiving FCARMS implantation or POEM therapy at the department of gastroenterology, the Seventh Medical Center of the Chinese People's Liberation Army General Hospital from May 2007 to May 2018. According to 
their previous treatment, they are divided into two groups, FCARMS group and POEM group. Clinical efficacy and complications were compared between the two groups.

Results: A total of 166 cases were collected, including 113 cases of FCARMS and 53 cases of POEM. By PS matching, 150 patients were enrolled (100 cases of FCARMS and 50 cases of POEM). By comparison, the FCARMS group has shorter operation time, shorter fasting time and lower hospitalization costs than the POEM group $(p<0.05)$. Common complications in the FCARMS group are nausea, vomiting, and stent shift. Repetitions of gastroscopy in the FCARMS group was more often, which were $3.8 \pm 2.4$ (vs $2.1 \pm 1.8$ of POEM) $(p=0.00<0.05$ ) The 6-month remission rates of the FCARMS combination POEM group were $89 \%$ and $94 \%$, respectively $(p=0.39)$, and the 2 -year remission rates were $61 \%$ and $90 \%$, respectively $(p=0.00)$.

Conclusions: Stent placement is a cost-effective and safe treatment option for achalasia. The short-term effect (less than 6 mons) of FCARMS is similar to that of POEM, the long-term effect (more than 2 years), POEM is better than FCARMS. HRM II is most suitable for POEM treatment. It indicate that Patients can choose treatment methods according to their own conditions.

Keywords fully coated anti-reflux metal stenting, per-oral endoscopic myotomy, achalasia.

\section{Background}

Achalasia is a rare primary esophageal motility disorder. Due to the lack of ganglion cells in the lower esophageal sphincter, the peristalsis of the lower esophagus disappears and the lower esophageal sphincter (LES) cannot relax.1 it is characterized of dysphagia, posterior sternal pain, regurgitation and weight losing, etc. However, there is currently no cure for achalasia ${ }^{2,3}$. The current treatment methods are mainly to reduce the pressure of the lower esophageal sphincter and relieve symptoms. Medications have little effect. The two commonly used drugs are nitrate and calcium channel blockers ${ }^{4}$. Laparoscopic Heller myotomy (LHM) is a surgical operation, with a success rate about $90 \%$ but adverse outcomes of Gastroesophageal reflux disease(GERD) achieved $25 \%$ and had to resort to 
acid-reducing medications5, beyond complications of trauma, scars, esophagus or gastric perforation6. Endoscopy treatments, such as Type A botulinum toxin injection, pneumatic dilation (PD), stents implantation and POEM have been used in recently. PD needs to be repeated every 2 to 4 weeks, about only one in third patients can reach 5 years remittance ${ }^{7,8,9,10}$. Type $A$ botulinum toxin is a biological neurotoxin released by Clostridium botulinum, which blocks the release of acetylcholine from voluntary and involuntary muscle nerve endings. The cost is higher than PD, the initial effect is better, the repeated effect is poor, and the maintenance time is short, about 6 to 9 months ${ }^{11,12}$. It's reported that stenting implantaiton treatment can relieve nearly 100 percent of achalasia patients for more than 8 years. Because the stent expands with uniform force, it is considered a safe and effective treatment ${ }^{13}$.

POEM is a new endoscopy technique for the treatment of achalasia originating from 2008. It is a form of per natural orifice transluminal endoscopic surgery that is completed by creating a submucosal tunnel in the lower part of esophagus to reach the inner circular muscle bundles of the LES to perform myotomy, while preserving the outer longitudinal muscle bundles. The short-term effect has been confirmed. However, it is still unclear which is better for achalasia, stenting or POEM $^{14}$ ? In this study, we will compare these two methods and find answers.

\section{Methods}

\section{Patients}

Data collected from cosective patients of Achalasia, definitively diagnosed by barium meals, endoscopy, and/or esophageal high resolution manometry, not treat with other methods, treated only with FCARMS implantation or POEM (treatment selcted according to patients' wishes)in the department of gastroenterology of the Seventh Medical Center of the Chinese People's Liberation Army General Hospital from May 2007 to May 2018. According to their previous treatment, they are divided into two 
groups, FCARMS group and POEM group. Divided into different subtypes according to gastroscopy, High-resolution manometry (HRM), and barium esophagram. This study protocol was approved by the Ethics Research Committee of the 7th medical center of the People's Liberation Army General Hospital, and the written informed consent of the person or his parents or legal guardians was obtained before each study.

\section{Equipment and procedure}

\section{Stent insertion and removal procedure}

Stents insertion and removal were performed under monitored anesthesia (propofol). First, gastroscopy estimates the distance from the esophagus-gastric junction to the incisor, then patients received FCARMS (MTN-SE C-membrane; 80-90mm; 18-20mm; MicroTech, Beijing, China) implantation, with anti-reflux silicone valve in distal and recycling wire in proximal. Patients had semisolid food on the day after stent placement and were given proton-pump inhibitor to prevent reflux esophagitis. Retrieval of the stent was performed with the help of a gastroscopy 3-7 days after stent placement. The stent was grasped by the retrieval lasso or the proximal stent wire and gently pulled out.

\section{POEM}

All POEM procedures were performed by Dr. Peng Jin and Dr. Jianqiu Sheng. The technique is based on previously described by Inoue and colleagues ${ }^{15}$. With endotracheal intubation, general anesthesia and $\mathrm{CO} 2$ insufflation. First, a sub-mucosal injection with normal saline, sodium hyaluronate and indigo carmine were made $5-10 \mathrm{~cm}$ above the gastroesophageal junction (GEJ), followed by a $2 \mathrm{~cm}$ longitudinal incision. Second, the submucosal layer was dissected to make a tunnel along the esophagus and across the GEJ $2-3 \mathrm{~cm}$ into the proximal stomach. Third, myotomy was started $3 \mathrm{~cm}$ below the tunnel entrance and extended $2-3 \mathrm{~cm}$ into the proximal stomach. The circular muscle fiber was dissected and the longitudinal muscle fiber was preserved. Finally, the submucosal entry was closed by metal clips. 
The esophageal myotomy length was measured above the LES. The gastric length was measured below the GEJ. After the procedure, patients received antibiotics and intravenous nutrition for 3 days, after which they began to take liquid food and gradually changed to solid food.

\section{Clinical symptom alleviation evaluation}

Clinical symptoms classification and efficacy are based on Eckardt Score of the questionnaire. The questionnaire will be collected by telephone or WeChat interview or outpatient service at 6 months after treatment, and then follow-up every year. The Eckardt score was used to assess the severity of achalasia symptoms as described by Eckardt16. It is based on four main symptoms, dysphagia, regurgitation, chest pain and weight loss. The final score is the sum of the four scores. Clinical curative effect was judged as follows ${ }^{17}$, 18: Eckardt score not more than 3 points was divided into remission, while not less than 4 points was divided into treatment failure; If patients received other treatment or re-implant the stent after shorter than half a year of relief, even if Eckardt score is less than 4, it will be classified as treatment failure either. It was considered successful if stents migrated in the stomach when final Eckardt socre less than 3 points.

\section{Classification}

\section{High resolution esophageal manometric (HRM) classification}

In 2008, the Chicago Classification was developed and researchers using HRM subdivided achalasia into three types. Type I, classic, is defined as achalasia with minimal esophageal pressurization, type II is defined as achalasia with panesophageal pressurization, and type III is defined as achalasia with spasm and premature contractions ${ }^{19}$. Patients received HRM (Sierra Scientific Instruments, San Diego, CA, USA) would be divided into three subtypes, which was according to modified Chicago Classification v3.020 (Figure 1). 


\section{Ling Classification}

Patients divided into three subtypes of Ling classification as described by Linghu EQ etc $^{21}$. Type I , smooth without multi-ring, crescent-like structure or diverticulum structure; type II , with multi-ring or crescent-like structure but without diverticulum structure; and type III, with diverticulum structure(Figure 2).

\section{Esophagography classification}

Barium swallow can help find aperistalsis, dilation of the esophagus, bird-beak appearance of the gastro-esophageal junction and delayed contrast medium emptying $^{22^{\prime} 23}$. Patients, according to the esophageal lumen maximal diameter, were divided into three levels: grade I, diameter $<3.5 \mathrm{~cm}$, expansion involving only lower esophagus; grade II , diameter between $3.5 \mathrm{~cm}$ to $6.0 \mathrm{~cm}$, expansion involving one third of lower esophagus; grade III diameter $>6.0 \mathrm{~cm}$, expansion involving two third of lower esophagus(Figure 3).

\section{Statistical analysis}

All statistical analyses were performed using SPSS version 26.0 (Chicago, USA). Use PS matching scoring method to reduce interfering factors such as age, gender, course of disease, LING type, barium esophagram type, Eckardt score and dysphagia score before treatment. Propensity sore match ${ }^{24}(1: 2)$ with capacity of 0.1 were used to delete non-matched data case in order to reduce confounding factors. Data conform to the normal distribution are expressed as Mean \pm SD. The independent $t$ test was used to compare the operating time, fasting time, postoperative hospital stay, average hospitalized cost, dysphagia score and weight-gaining between the two 
groups. Pearson chi-square test was used to compare percentages of curative efficiency and complications among the groups. In all instances, $\mathrm{P}$ value $<0.05$ is considered significant differences.

\section{Results}

A total of 166 cases, after PS matching, left 150 (FCARMS group $n=100$, POEM group $n=50$ ) patients into the study. There was no difference between the two groups in general age, gender, course of disease, Eckardt score and dysphagia score before treatment $(p=0.65,1.00,0.44,0.40,1.00>0.05)($ table 1$)$. There are three subtypes of HRM, LING, and Barium esophagography classifications. There is no significant difference in the number of patients in each subtype between the two groups. $(P=0.31,0.60,0.27,>0.05)$ (table 1$)$. The results of HRM and Ling' subtype classifications didn't affect remission rate $(p=0.20,0.58,0.94 ; p=0.37,0.67$, $0.63>0.05$ ) (table 4). By contrast, the FCARMS group requires shorter operating time, shorter fasting time and lower hospitalization costs than the POEM group $(8.41 \pm$ 4.88 VS $73.94 \pm 41.61$ minutes, $2.24 \pm 1.65$ vs $4.58 \pm 2.50$ day,$¥ 17787.85 \pm 3711.69$ vs $27705.41 \pm 8868.09, p=0.00,0.00,0.00<0.05$ ) (table 2 ). The repetition times of gastroscopy in the two groups were $3.8 \pm 2.4$ and $2.1 \pm 1.8$ times respectively, the difference was significant $(P=0.00<0.05)$. The more complications in the FCARMS group were nausea, vomiting, and stent displacement $(p=0.00,0.00<0.05)$. While in the POEM group, it had a higher perforation incidence $(P=0.01<0.05)$. The other complications of bleeding, fever, chest pain and abdominal pain had no significant 
difference between the two groups ( $p=0.34,0.34,0.36,0.13>0.05$ ) (table 2$)$. At 6 months, the dysphagia was significantly relived in both groups $(p=0.01<0.05)$ (table 2$)$ (Figure 4). The 6-month remission rates of the FCARMS combination POEM group were $89 \%$ and $94 \%$, respectively $(p=0.3$. At One and two years follow-up, the POEM group had a better remission rate than the FCARMS group ( $92 \%$ vs $76 \%, 90 \%$ vs $61 \%$, $p=0.03,0.00<0.05$ ) (table 3 ). In 2 years follow up, barium esophagram grade I has the highest remission rate $(p=001,0.00,0.03<0.05)$ (table 4$)$. Overall analysis, there is no difference in curative effect between each type of Ling's classification $(p=0.37$, $0.67,0.63>0.05)$ and between each type of HRM classification ( $p=0.20,0.58$, $0.94>0.05)$. HRM classification, the remission rate of type II at 2 years in the POEM group $(100 \%)$ is higher than that of the FCARMS group $(64.3 \%)(p=0.02)$, and the remission rate of HRM III in the two groups is equivalent( $>>0.05)$, not as good as HRM II (table 5).

\section{Discussion}

Achalasia is a primary esophageal motility disorder, characterized by aperistalsis in the distal portion of the esophageal body and incomplete or absent relaxation of the lower esophageal sphincter (LES). AS an incurable disease, the aim of treatment is to reduce LES pressure and solve the problem of dysphagia. Stent insertion treatment of achalasia was first described by De Palma in 1998 with encouraging results, originally used as a last resort in patients who had failed medical therapy or pneumatic dilation, or who were poor surgical candidates ${ }^{25}$. A study had reported 
that short-term stent placement in the treatment of achalasia is safe and effective, with good long-term clinical remission15. Undeniably, in this study, we found that the FCARMS implantation therapy has the advantages of short operation time, short fasting time, and low hospitalization costs. As a special expander, the stent has the characteristics of uniform force, which reduces the risk of perforation. The stent upper line shrinks made it facilitate remove. Yet it can be reused when the disease recurs. The operation is simple and safe, and alleviate dysphagia quickly, besides, the hospital stay is short, so the cost reduced. These advantages are especially suitable for patients who are at high risk of anesthesia or who have a short survival period but urgently need to solve swallowing difficulties. Since the short-term effects, it requires more repetitions of gastroscopy. As the follow-up time is extended, the remission rate decreases, which may explain why the FCARMS group repeated endoscopy more often.

In this study, we adopt the PS matching analysis method to reduce the interference factors, making the research more accurate and the results more reliable. There is no significant difference in the number of the same HRM, Ling' $s$ and barium esophagram subtype classification in the two groups. At 6 months, the dysphagia and weight-gaining were improved remarkable in both groups (Figure $4 \&$ 5). At 1-year and 2-year, POEM had a much higher curative rate than FCARMS, the remission rate was $92.0 \%$ and $90.0 \%$, respectively $(p=0.03,0.00<0.05)$ (table 3$)$.For people with a long survival period more than 2 years, no risk of anesthesia, reluctance to repeat gastroscopy, or good economic conditions, POEM may be more 
appropriate, which still need further research.

It was reported that $30 \mathrm{~mm}$ diameter stents shift rate was $5.33 \%$, much lower than our study (25\%), if change the diameter may be a modified method.26 In this study, patients received stent with diameter of $18-20 \mathrm{~mm}$. The covered stent has a barbed needle to prevent the stent from moving up. So it falls into the stomach more often. Stent and POEM has equivalence effect at six-month follow-up $(p=0.39>0.05)$ but as time goes, POEM had a better curative rate at 1-year and 2-year follow-up. Maybe it implies POEM has a better further long-term curative efficacy than stent. It is still need for further study to decrease complications and enhance curative effect. In our digestive endoscopy center, technology of POEM has carried out not long enough, but the stent implantation treatment has been developed for over 13 years, over $32 \%$ of patients' dysphagia remittance over 10 years and $100 \%$ over 5 years by repeated short-time stent implantation. They are still under further follow-up.

Similar to previous reported, Ling classification subtype I was the most common type of achalasia and account for $88 \%$ while subtype III was the least type and only $2 \%$ in this study. Yet it is a limitation to our study, in the LING 's type III, only two patients in the FCARMS group and zero in the POEM group. Similarly, in the HRM type I , only four patients in the FCARMS group and zero in the POEM group. A larger sample and a prospective study are required for more accurate and more meaningful data.

The remission rate of three grades of barium esophagram was also significant difference within two years follow-up $(p=0.01,0.00,0.03<0.05)$ (table 4). Barium 
esophagram grade I had the best remission rate than other two grades, the curative efficiency reduced along with barium esophagram grading increasing. Barium esophagram grading according to esophageal maximal lumen diameter, which related to progress of the achalasia ${ }^{25}$. What imply earlier treatment curative effect is better. But the Ling' subtype classifications didn't affect remission rate $(p=0.37,0.67$, $0.63>0.05$ ) (table 4).

HRM classification type II achalasia used to be reported had the best response to PD and LHM treatment ${ }^{27}$. Data of this study is not different to previous report, in POEM group, we discovered that HRM II classification had the best remission rate among three subtypes within 2 years follow up $(p=0.20,0.58,0.94>0.05)$. In the FCARMS group, the highest clinical efficacy rate was 100\% (29/29) of HRM typeIIIand $92.9 \%(26 / 28)$ of HRM type II in stent group at six month follow-up(table 5$)$. It shows that within 1 year, HRM classification II , III, FCARMS and POEM treatment methods are all effective(table 5). HRM classification II had the best response to POEM at 2 years follow up. HRM II in POEM group had a remission rate reached to $100 \%$ within two years follow-up. HRM type II is defined as achalasia with panesophageal pressurization. After POEM, the circular muscle of the lower esophageal sphincter was incised, the muscle relaxes, the pressure decreases, and the symptoms of dysphagia are relieved. This explains why HRM II is most suitable for POEM treatment.

As we known, HRM type III is featured with spasm, always considered most difficult to relieve ${ }^{28}$, but in this study we found FCARMS had a remission rate up to 
$100 \%$ in HRM type III. In this study, HRM type III, the stent and POEM group had equivalence curative efficiency for two years follow-up. HRM III can be treated by both methods. The stent needed only pay once, preserve if removed, when dysphagia recurred can be reused, made more cost-effective. By contrast, stent implantation cost shorter operating time and less fee yet no serious complications. For elderly patients, especially those with cerebrovascular disease cannot undergo long endoscopic operation and prolonged anesthesia but were badly in need of solution dysphagia, stent is an appropriate choice.

\section{Conclusions}

Stent placement is a cost-effective and safe treatment option for achalasia. The short-term effect (less than 6 mons) of FCARMS is similar to that of POEM, the long-term effect (more than 2 years), POEM is better than FCARMS. HRM II is most suitable for POEM treatment. Our results indicate that Patients can choose treatment methods according to their own conditions. 
Table1 the two groups of achalasia patients' general information before treatment by propensity sore match

\begin{tabular}{llll}
\hline & Stent group $(\mathrm{n}=100)$ & POEM group $(\mathrm{n}=50)$ & $\mathrm{P}$ \\
\cline { 2 - 4 } Age (year) & $40.09 \pm 14.94$ & $41.20 \pm 12.86$ & 0.65 \\
gender (male/female) & $51 / 49$ & $25 / 25$ & 1.00 \\
Course of disease (year) & $5.81 \pm 5.90$ & $6.78 \pm 7.83$ & 0.44 \\
Classification* & & & \\
HRM I/II/III (n) & $4 / 28 / 29$ & $0 / 14 / 19$ & 0.31 \\
Ling I / II/III (n) & $58 / 40 / 2$ & $30 / 20 / 0$ & 0.60 \\
Barium meal I/ II/III(n) & $54 / 35 / 11$ & $20 / 23 / 7$ & 0.27 \\
Eckardt score & $7.21 \pm 1.78$ & $6.96 \pm 1.69$ & 0.40 \\
Dysphagia score & $2.98 \pm 0.14$ & $2.98 \pm 0.14$ & 1.00 \\
\hline
\end{tabular}

${ }^{*}$ Chi-square test, T-test, $\mathrm{P}>0.05$, no significant difference. 
Table 2 the two group's comparison of the operating time, fasting time, complications, hospitalized cost and symptoms response at 6 months after treatment.

\begin{tabular}{|c|c|c|c|}
\hline & $\begin{array}{l}\text { Stent group } \\
(n=100)\end{array}$ & $\begin{array}{l}\text { POEM group } \\
(n=50)\end{array}$ & $\mathrm{P}$ \\
\hline Operating time ${ }^{* *}(\min )$ & $8.41 \pm 4.88$ & $73.94 \pm 41.61$ & 0.00 \\
\hline Fasting time (day) & $2.24 \pm 1.65$ & $4.58 \pm 2.50$ & 0.00 \\
\hline Postoperative hospital stay (day) & $5.73 \pm 2.97$ & $6.22 \pm 2.50$ & 0.32 \\
\hline Complications* perforated & $0(0 \%)$ & $6(11.3 \%)$ & 0.01 \\
\hline bleeding & $10(10.0 \%)$ & $2(4.0 \%)$ & 0.34 \\
\hline fever & $13(13.0 \%)$ & $10(20.0 \%)$ & 0.34 \\
\hline chest pain & $37(37.0 \%)$ & $14(28.0 \%)$ & 0.36 \\
\hline abdominal pain & $10(10.0 \%)$ & $10(20.0 \%)$ & 0.13 \\
\hline Nausea vomiting & $30(30.0 \%)$ & $1(2.0 \%)$ & 0.00 \\
\hline Migration & $25(25.0 \%)$ & - & - \\
\hline Number of repetitions of gastroscopy & $3.8 \pm 2.4$ & $2.1 \pm 1.8$ & 0.00 \\
\hline acid reflux and heart burning & $2(2.0 \%)$ & $0(0 \%)$ & 0.00 \\
\hline The average hospitalization cost ${ }^{\#}$ ( $\left.¥\right)$ & $17787.85 \pm 3711.69$ & $27705.41 \pm 8868.09$ & 0.00 \\
\hline \multicolumn{4}{|l|}{ Symptomatic response at 6 months } \\
\hline dysphagia score ${ }^{\# \#}$ & $0.95 \pm 0.92$ & $0.58 \pm 0.60$ & 0.01 \\
\hline Weight-gaining (kg) & $5.26 \pm 3.04$ & $5.75 \pm 4.26$ & 0.31 \\
\hline
\end{tabular}

T-test for Equality of means. *Fisher's exact test, $\mathrm{P}>0.05$, no significant difference; $\mathrm{P}<0.05$, significant differences. \# Expenses include the cost of nursing, evaluation, surgery, and medication during hospitalization.

**operating times calculated:Operation time calculation for stent placement: the time between the first gastroscopic picture and the picture after the stent is placed POEM operation time: the time between the esophagus incision and the complete clipping of the incision

\#\#dysphagia score is part of the Ecardt scores 
Table 3 Curative efficacy comparison between two groups after treatment at 6-month, 1-year, and 2-year

\begin{tabular}{|c|c|c|c|c|}
\hline \multirow{2}{*}{$\begin{array}{l}\text { Follow } \\
\text { data }\end{array}$} & up & FCARMS group $(\mathrm{n}=100)$ & POEM group $(\mathrm{n}=50)$ & $\mathrm{P}$ \\
\hline & & Remission failure & Remission failure & \\
\hline 6-month & & $89(89.0 \%) 11(10.0 \%)$ & $47(94.0 \%) 3(6.0 \%)$ & 0.39 \\
\hline 1-year & & $76(76.0 \%) 24(24.0 \%)$ & $46(92.0 \%) 4(8.0 \%)$ & 0.03 \\
\hline 2-year & & $61(61.0 \%) 39(39.0 \%)$ & $45(90.0 \%) 5(10.0 \%)$ & 0.00 \\
\hline
\end{tabular}

Fisher's exact test, $\mathrm{P}>0.05$, no significant difference; $\mathrm{P}<0.05$, significant differences.

Table 4 Curative efficacy comparison among Ling' subtype classifications, Barium meal grading and HRM classifications at 6-month, 1-year, and 2-year follow-up.

\begin{tabular}{|c|c|c|c|c|c|c|c|c|c|c|c|c|c|}
\hline & & \multicolumn{3}{|c|}{$\begin{array}{l}\text { Ling' } \\
\text { classification(n) }\end{array}$} & \multirow[t]{2}{*}{$\mathrm{P}$} & \multicolumn{3}{|c|}{$\begin{array}{l}\text { Barium } \\
\text { esophagram } \\
\text { grade }(n)\end{array}$} & \multirow[t]{2}{*}{$\mathrm{P}$} & \multicolumn{3}{|c|}{$\begin{array}{l}\text { HRM } \\
\text { classification(n) }\end{array}$} & $P$ \\
\hline & & I & II & III & & I & II & III & & I & II & III & \\
\hline \multicolumn{2}{|c|}{ 6-month Remission } & 82 & 52 & 2 & 0.37 & 71 & 53 & 12 & 0.01 & 3 & 40 & 46 & 0.20 \\
\hline & failure & 6 & 8 & 0 & & 3 & 5 & 6 & & 1 & 2 & 2 & \\
\hline \multirow[t]{2}{*}{ 1-year } & Remission & 70 & 50 & 2 & 0.67 & 63 & 51 & 8 & 0.00 & 3 & 38 & 41 & 0.58 \\
\hline & failure & 18 & 10 & 0 & & 11 & 7 & 10 & & 1 & 4 & 7 & \\
\hline \multirow[t]{2}{*}{ 2-year } & Remission & 61 & 43 & 2 & 0.63 & 53 & 45 & 8 & 0.03 & 3 & 32 & 35 & 0.94 \\
\hline & failure & 27 & 17 & 0 & & 21 & 3 & 10 & & 1 & 10 & 13 & \\
\hline
\end{tabular}

Fisher's exact test, $\mathrm{P}>0.05$, no significant difference; $\mathrm{P}<0.05$, significant differences. 
Table 5 curative effect comparison between FCARMS and POEM group in the same HRM classification at 6-month, 1-year, and 2-year follow-up.

\begin{tabular}{|c|c|c|c|c|c|c|c|c|c|c|}
\hline \multirow{2}{*}{\multicolumn{2}{|c|}{$\begin{array}{c}\text { HRM } \\
\text { classification }\end{array}$}} & \multicolumn{2}{|c|}{ 6-month } & \multirow[t]{2}{*}{$\mathrm{P}$} & \multicolumn{2}{|l|}{ 1-year } & \multirow[t]{2}{*}{$\mathrm{P}$} & \multicolumn{2}{|l|}{ 2-year } & \multirow[t]{2}{*}{$\mathrm{P}$} \\
\hline & & $\begin{array}{l}\text { Remission } \\
\mathrm{n}(\%)\end{array}$ & $\begin{array}{l}\text { Failure } \\
\mathrm{n}(\%)\end{array}$ & & $\begin{array}{l}\text { Remission } \\
\mathrm{n}(\%)\end{array}$ & $\begin{array}{l}\text { Failure } \\
\text { n }(\%)\end{array}$ & & $\begin{array}{c}\text { Remission } \\
\mathrm{n}(\%)\end{array}$ & $\begin{array}{l}\text { Failure } \\
\text { n }(\%)\end{array}$ & \\
\hline \multirow[t]{2}{*}{ I } & FCARMS & $3(75)$ & $1(25)$ & - & $3(75)$ & $1(25)$ & - & $3(75)$ & $1(25)$ & - \\
\hline & POEM & 0 & 0 & & 0 & 0 & & 0 & 0 & \\
\hline \multirow[t]{2}{*}{ II } & FCARMS & $26(92.9)$ & $2(7.1)$ & 0.55 & $24(85.7)$ & $4(14.3)$ & 0.28 & $18(64.3)$ & $10(35.7)$ & 0.02 \\
\hline & POEM & $14(100)$ & 0 & & $14(100)$ & 0 & & $14(100)$ & $0(0)$ & \\
\hline \multicolumn{2}{|c|}{ IIIFCARMS } & $29(100)$ & $0(0)$ & 0.15 & $25(86.2)$ & $4(13.8)$ & 1.00 & $19(65.5)$ & $10(34.5)$ & 0.20 \\
\hline & POEM & $17(89.5)$ & $2(10.5)$ & & $16(84.2)$ & $3(15.8)$ & & $16(84.2)$ & $3(15.8)$ & \\
\hline
\end{tabular}




\section{Figure Legends}

Figure 1: Typical pictures of three types of HRM classification before and after stent treatment. A: type I achalasia before treatment, no esophageal contraction and no esophageal pressurization. B: Type II achalasia before treatment, is characterized by panesophageal pressurization and absence of a peristaltic contraction. C: type III achalasia before treatment, there are at least $20 \%$ premature contractions, defined as $\mathrm{DL}<4.5 \mathrm{~s}$. D: type I achalasia after treatment, low esophageal pressure decrease after stent insertion for one month and removed. E: type II achalasia after treatment, panesophageal pressure reduced, peristaltic contraction appeared. F: type III achalasia after stent treatment, Spastic hypertension disappeared.

Figure 2: Typical pictures of each type or subtype in Ling classification. A: Type I ; B: Type II a; C: Type II b; D: Type II c; E: Type IIII; F: Type IIIr; G: Type IIIllr.

Figure 3: Typical pictures of Barium esophagram gradings. A: grade I; B: grade II, C: grade III

Figure 4: Typical pictures before and after receiving stenting treatment. A: cardia satus before treatment under endoscopy B: cardia satus after treatment under endoscopy C: beak shape under barium esophagram before treatment D: barium smoothly through the cardia after treatment.

Figure 5: Typical pictures before and after receiving POEM treatment. A: cardia satus before treatment under endoscopy B: cardia satus after treatment under endoscopy C: barium retention in the lower esophagus before treatment $\mathrm{D}$ : barium smoothly through the cardia after treatment. 


\section{Abbreviations}

FCARMS: Fully coated anti-reflux metal stent; POEM: Per-oral endoscopic myotomy; PS: Propensity score; LES: Lower esophageal sphincter; PD: Pneumatic dilation; LHM:Laparoscopic Heller myotomy; HRM:High-resolution manometry;GEJ:Gastroesophageal junction.

\section{Acknowledgements}

We thank all participants in this research.

\section{Authors' contributions}

Yufen Tang drafted the manuscript,collected data and carried out data analysis; Yufen Tang prepared figures 1-5; Jianqiu Sheng and Peng Jin participated in study design and operated on the subjects. Yurong Tao reviewd this article. All authors read and approved the final manuscript.

\section{Funding}

Not applicable

\section{Availability of data and materials}

The datasets and materials used during the current study are available from the corresponding author on reasonable request.

\section{Ethics approval and consent to participate}

All methods in this study were carried out in accordance with relevant guidelines and regulations. This study protocol was approved by the Ethics Research Committee of the seventh medical center of the People's Liberation Army General Hospital. All patients provided written, informed consent to participate in the study.

\section{Consent for publication}

Not applicable

\section{Competing interests}

All authors declare no conflict of interest in this study.

\section{Author details}

1 Department of Gastroenterology, the seventh Medical Center of PLA General Hospital, Beijing, China; ${ }^{2}$ Senior Department of Gastroenterology, the First Medical Center of PLA General Hospital, Beijing, China.

\section{References}

1 Ahmed Y, Othman MO. Peroral endoscopic myotomy (POEM) for achalasia. J Thorac Dis. 2019 Aug;11(Suppl12):S1618S1628.doi:10.21037/jtd.2019.07.84.PMID:31489229;PMCID:PMC670239.

2 Boeckxstaens GE, Zaninotto G, Richter JE. Achalasia. Lancet. 2014 Jan 4;383(9911):83-93. doi: 10.1016/S0140-6736(13)60651-0. Epub 2013 Jul 17. PMID: 23871090.

3 Torresan F, Ioannou A, Azzaroli F, Bazzoli F. Treatment of achalasia in the era of high-resolution manometry. Ann Gastroenterol. 2015 Jul-Sep;28(3):301-308. PMID: 26130022; PMCID: 
PMC4480166.

4 Beck WC, Sharp KW. Achalasia. Surg Clin North Am. 2011 Oct;91(5):1031-7. doi: 10.1016/j.suc.2011.06.005. PMID: 21889028.

5 Allaix ME, Patti MG. What is the best primary therapy for achalasia: medical or surgical treatment? Who owns achalasia? J Gastrointest Surg. 2013 Sep;17(9):1547-9. doi: 10.1007/s11605-013-2252-z. Epub 2013 Jun 19. PMID: 23780637.

6 Schlottmann F, Luckett DJ, Fine J, Shaheen NJ, Patti MG. Laparoscopic Heller Myotomy Versus Peroral Endoscopic Myotomy (POEM) for Achalasia: A Systematic Review and Meta-analysis. Ann Surg. 2018 Mar;267(3):451-460. doi:10.1097/SLA.0000000000002311. PMID: 28549006.

7 Chuah SK, Chiu CH, Tai WC, Lee JH, Lu HI, Changchien CS, Tseng PH, Wu KL. Current status in the treatment options for esophageal achalasia. World J Gastroenterol. 2013 Sep 7;19(33):5421-9. doi: 10.3748/wjg.v19.i33.5421. PMID: 24023484; PMCID: PMC3761094.

8 von Renteln D, Inoue H, Minami H, Werner YB, Pace A, Kersten JF, Much CC, Schachschal G, Mann O, Keller J, Fuchs KH, Rösch T. Peroral endoscopic myotomy for the treatment of achalasia: a prospective single center study.Am J Gastroenterol.

2012Mar;107(3):4117.doi:10.1038/ajg.2011.388.Epub 2011 Nov 8.PMID: 22068665.

9 Richter JE. Update on the management of achalasia: balloons, surgery and drugs. Expert Rev Gastroenterol Hepatol. 2008 Jun;2(3):435-45. doi: 10.1586/17474124.2.3.435. PMID: 19072391.

10 Jung HE, Lee JS, Lee TH, Kim JN, Hong SJ, Kim JO, Kim HG, Jeon SR, Cho JY. Long-term outcomes of balloon dilation versus botulinum toxin injection in patients with primary achalasia. Korean J Intern Med. 2014 Nov;29(6):738-45. doi: 10.3904/kjim.2014.29.6.738. Epub 2014 Oct 31. PMID: 25378972; PMCID: PMC4219963.

11 Lynch KL, Pandolfino JE, Howden CW, Kahrilas PJ. Major complications of pneumatic dilation and Heller myotomy for achalasia: single-center experience and systematic review of the literature. Am J Gastroenterol. 2012 Dec;107(12):1817-25. doi: 10.1038/ajg.2012.332. Epub 2012 Oct 2. PMID: 23032978; PMCID: PMC3808165.

12 Zhao JG, Li YD, Cheng YS, Li MH, Chen NW, Chen WX, Shang KZ. Long-term safety and outcome of a temporary self-expanding metallic stent for achalasia: a prospective study with a 13-year single-center experience. Eur Radiol. 2009 Aug;19(8):1973-80. doi: 10.1007/s00330-009-1373-y. Epub 2009 Mar 19. PMID: 19296113; PMCID: PMC2705705.

13 Zeng Y, Dai YM, Wan XJ. Clinical remission following endoscopic placement of retrievable, fully covered metal stents in patients with esophageal achalasia. Dis Esophagus. 2014 Feb-Mar;27(2):103-8. doi: 10.1111/dote.12083. Epub 2013 Jun 24. PMID: 23796127.

14 Zhao H, Wan XJ, Yang CQ. Comparison of endoscopic balloon dilation with metal stent placement in the treatment of achalasia. J Dig Dis. 2015 Jun;16(6):311-8. doi: 10.1111/1751-2980.12241. PMID: 25765898.

15 Inoue H, Minami H, Kobayashi $Y$, et al. Peroral endoscopic myotomy (POEM) for esophageal achalasia. Endoscopy.2010;42:265-271. doi: 10.1055/s-0029-1244080.

16 Eckardt VF. Clinical presentations and complications of achalasia. Gastrointest Endosc Clin N Am. 2001; 11(2):281-92. PMID: 11319062

17 Wang HM, Tai WC, Chuah SK, Lu HI, Lu LS, Liang CM, Kuo CH, Chiu YC, Wu KL, Changchien CS. Comparison of treatment outcomes of endoscope-guided pneumatic dilation and laparoscopic Heller myotomy. Kaohsiung J Med Sci. 2015 Dec;31(12):639-43. doi: 10.1016/j.kjms.2015.10.003. Epub 2015 Nov 30. PMID: 26709226.

18 Arora Z, Thota PN, Sanaka MR. Achalasia: current therapeutic options. Ther Adv Chronic Dis. 2017 Jun;8(6-7):101-108. doi: 10.1177/2040622317710010. Epub 2017 Jun 23. PMID: 28717439; PMCID: PMC5502956.

19 Pandolfino JE, Kwiatek MA, Nealis T, Bulsiewicz W, Post J, Kahrilas PJ (2008) Achalasia: a new clinically relevant classifi- cation by high-resolution manometry. Gastroenterology 135(5):1526-1533

20 Kahrilas PJ, Bredenoord AJ, Fox M, Gyawali CP, Roman S, Smout AJ, Pandolfino JE; International High Resolution Manometry Working Group. The Chicago Classification of esophageal motility disorders, v3.0. Neurogastroenterol Motil. 2015 Feb;27(2):160-74. doi: 
10.1111/nmo.12477. Epub 2014 Dec 3. PMID: 25469569; PMCID: PMC4308501.

$21 \mathrm{Li} \mathrm{HK}$, Linghu EQ. New endoscopic classification of achalasia for selection of candidates for peroral endoscopic myotomy. World J Gastroenterol. 2013 Jan 28;19(4):556-60. doi: 10.3748/wjg.v19.i4.556. PMID: 23382636; PMCID: PMC3558581.

22 Pandolfino JE, Kahrilas PJ. Presentation, diagnosis, and management of achalasia. Clin Gastroenterol Hepatol. 2013 Aug;11(8):887-97. doi: 10.1016/j.cgh.2013.01.032. Epub 2013 Feb 8. PMID: 23395699.

23 Omura N, Kashiwagi H, Ishibashi Y, Yano F, Tsuboi K, Kawasaki N, Suzuki Y, Yanaga K. Laparoscopic Heller myotomy and Dor fundoplication for the treatment of achalasia. Assessment in relation to morphologic type.Surg Endosc.2006Feb;20(2):210-3.doi:

10.1007/s00464-005-0365-5. Epub 2005 Nov 21. PMID: 16328672.

24 Kuss O, Blettner M, Börgermann J. Propensity Score: an Alternative Method of Analyzing Treatment Effects.Dtsch Arztebl Int.2016Sep5;113(35-36):597-603.doi:10.3238/arztebl.2016.0597. PMID: 27658473; PMCID: PMC5963493.

25 De Palma GD, Catanzano C (1998) Removable self-expanding metal stents: a pilot study for treatment of achalasia of the esophagus. Endoscopy 30:S95-S96

26 Sioulas AD, Malli C, Dimitriadis GD, Triantafyllou K. Self-expandable metal stents for achalasia: Thinking out of the box! World J Gastrointest Endosc. 2015 Jan 16;7(1):45-52. doi: 10.4253/wjge.v7.i1.45. PMID: 25610533; PMCID: PMC4295180.

27 Salvador R, Costantini M, Zaninotto G, Morbin T, Rizzetto C, Zanatta L, Ceolin M, Finotti E, Nicoletti L, Da Dalt G, Cavallin F, Ancona E. The preoperative manometric pattern predicts the outcome of surgical treatment for esophageal achalasia. J Gastrointest Surg. 2010 Nov; 14(11):1635-45. doi: 10.1007/s11605-010-1318-4. Epub 2010 Sep 10. PMID: 20830530.

28 Stavropoulos SN, Modayil R, Friedel D. Per oral endoscopic myotomy for the treatment of achalasia.Curr Opin Gastroenterol.2015 Sep;31(5):430-40.doi: 10.1097/MOG.0000000000000206. PMID: 26200001. 


\section{Figures}

\section{Figure 1}

Typical pictures of three types of HRM classification before and after stent treatment. A: type I achalasia before treatment, no esophageal contraction and no esophageal pressurization. B: Type II achalasia before treatment, is characterized by panesophageal pressurization and absence of a peristaltic contraction. C: type III achalasia before treatment, there are at least $20 \%$ premature contractions, defined as $\mathrm{DL}<4.5 \mathrm{~s}$. D: type I achalasia after treatment, low esophageal pressure decrease after stent insertion for one month and removed. E: type II achalasia after treatment, panesophageal pressure reduced, peristaltic contraction appeared. F: type III achalasia after stent treatment, Spastic hypertension disappeared.

\section{Figure 2}

Typical pictures of each type or subtype in Ling classification. A: Type『; B: Type 『a; C: Type 『b; D: Type 『c;

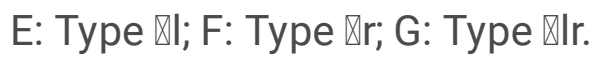
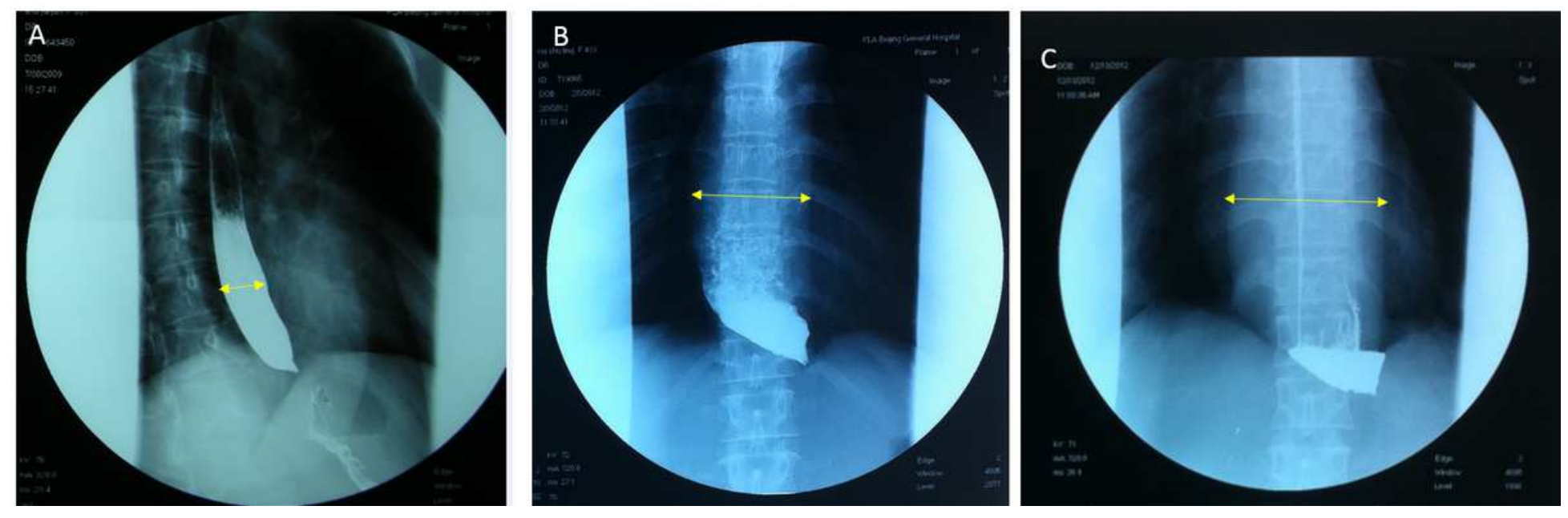

\section{Figure 3}

Typical pictures of Barium esophagram gradings. A: grade I; B: grade II, C: grade III 展

\section{Figure 4}

Typical pictures before and after receiving stenting treatment. A: cardia satus before treatment under endoscopy B: cardia satus after treatment under endoscopy C: beak shape under barium esophagram before treatment $\mathrm{D}$ : barium smoothly through the cardia after treatment. 


\section{Figure 5}

Typical pictures before and after receiving POEM treatment. A: cardia satus before treatment under endoscopy B: cardia satus after treatment under endoscopy $\mathrm{C}$ : barium retention in the lower esophagus before treatment $\mathrm{D}$ : barium smoothly through the cardia after treatment. 